\title{
Comment on "Measurement and Correlation of Solubilities of (Z)-2- (2-Aminothiazol-4-yl)-2-methoxyiminoacetic Acid in Different Pure Solvents and Binary Mixtures of Water + (Ethanol, Methanol, or Glycol)"
}

Abolghasem Jouyban, ${ }^{* \dagger}{ }^{\dagger}$ Mohammad A. A. Fakhree, ${ }^{\ddagger}$ and William Eugene Acree, Jr. ${ }^{\S}$

${ }^{\dagger}$ Drug Applied Research Center and Faculty of Pharmacy, Tabriz University of Medical Sciences, Tabriz 51664, Iran

${ }^{\ddagger}$ Tuberculosis and Lung Disease Research Center, Tabriz University of Medical Sciences, Tabriz 51664, Iran

${ }^{\S}$ Department of Chemistry, University of North Texas, Denton, Texas 76203-5070, United States

T $\mathrm{n}$ a recent paper in this journal, Zhou et al. ${ }^{1}$ reported the 1 experimental solubility data of (Z)-2-(2-aminothiazol-4-yl)2-methoxyiminoacetic acid (a pharmaceutical intermediate compound) in water, methanol, ethanol, glycol, and 1-propanol and the binary mixtures of water + methanol, water + ethanol, and water + glycol at different temperatures using a laser monitoring technique. The authors correlated the solubility data in binary solvent mixtures at various temperatures using a modified version of the Jouyban-Acree model and reported the accuracy of calculations using the mean percentage deviation (MPD) values computed by

$$
\mathrm{MPD}=\frac{100}{N} \sum \frac{\left|x_{\mathrm{A}}^{\mathrm{cal}}-x_{\mathrm{A}}\right|}{x_{\mathrm{A}}}
$$

where $N$ is the number of experimental data points, $x_{\mathrm{A}}^{\mathrm{cal}}$ is the correlated solubility, and $x_{\mathrm{A}}$ is the experimental solubility of the solute in the binary solvent mixtures. The basic Jouyban-Acree model for representing the solubility of drugs in binary solvent mixtures at various temperatures is

$$
\begin{aligned}
\ln x_{\mathrm{A}, T}= & x_{\mathrm{B}}^{0} \ln \left(x_{\mathrm{A}}\right)_{\mathrm{B}, T}+x_{\mathrm{C}}^{0} \ln \left(x_{\mathrm{A}}\right)_{\mathrm{C}, T} \\
& +x_{\mathrm{B}}^{0} x_{\mathrm{C}}^{0} \sum_{i=0}^{n} \frac{J_{i}}{T}\left(x_{\mathrm{B}}^{0}-x_{\mathrm{C}}^{0}\right)^{i}
\end{aligned}
$$

where $x_{\mathrm{B}}^{0}$ and $x_{\mathrm{C}}^{0}$ are the mass fractions of solvents $\mathrm{B}$ (water) and $C$ (methanol, ethanol, or glycol) in the absence of the solute, $\left(x_{\mathrm{A}}\right)_{\mathrm{B}, T}$ and $\left(x_{\mathrm{A}}\right)_{\mathrm{C}, T}$ are the mole fraction solubilities of the solute in the monosolvents $\mathrm{B}$ and $\mathrm{C}, \mathrm{T}$ is the absolute temperature, and the $J_{i}$ terms are the model constants computed using a no-intercept least-squares analysis. ${ }^{2}$ It is possible to replace $x_{\mathrm{C}}^{0}$ by $\left(1-x_{\mathrm{B}}^{0}\right)$ in eq 2 , and with $n=2$ the equation can be rearranged as ${ }^{3}$

$$
\begin{aligned}
\ln x_{\mathrm{A}, T}= & \ln \left(x_{\mathrm{A}}\right)_{\mathrm{C}, T}+\left[\ln \left(x_{\mathrm{A}}\right)_{\mathrm{B}, T}-\ln \left(x_{\mathrm{A}}\right)_{\mathrm{C}, T}\right] x_{\mathrm{B}}^{0} \\
& +\left[J_{0}-J_{1}+J_{2}\right] \frac{\left(x_{\mathrm{B}}^{0}\right)}{T}+\left[3 J_{1}-J_{0}-5 J_{2}\right] \\
& \frac{\left(x_{\mathrm{B}}^{0}\right)^{2}}{T}+\left[8 J_{2}-2 J_{1}\right] \frac{\left(x_{\mathrm{B}}^{0}\right)^{3}}{T}+\left[-4 J_{2}\right] \frac{\left(x_{\mathrm{B}}^{0}\right)^{4}}{T}
\end{aligned}
$$

The $\ln \left(x_{\mathrm{A}}\right)_{\mathrm{B}, T}$ and $\ln \left(x_{\mathrm{A}}\right)_{\mathrm{C}, T}$ could be replaced with the corresponding values from a semiempirical model $^{4}$ as

$$
\begin{aligned}
& \ln \left(x_{\mathrm{A}}\right)_{\mathrm{B}, T}=a_{1}+\frac{b_{1}}{T}+c_{1} \ln T \\
& \ln \left(x_{\mathrm{A}}\right)_{\mathrm{C}, T}=a_{2}+\frac{b_{2}}{T}+c_{2} \ln T
\end{aligned}
$$

By combination of eqs 3, 4, and 5 and further rearrangements, Zhou et al. obtained

$$
\begin{aligned}
\ln x_{\mathrm{A}, T}= & A_{1}+\frac{A_{2}}{T}+A_{3} \ln T+A_{4} x_{\mathrm{B}}^{0}+A_{5} \frac{\left(x_{\mathrm{B}}^{0}\right)}{T} \\
& +A_{6} \frac{\left(x_{\mathrm{B}}^{0}\right)^{2}}{T}+A_{7} \frac{\left(x_{\mathrm{B}}^{0}\right)^{3}}{T}+A_{8} \frac{\left(x_{\mathrm{B}}^{0}\right)^{4}}{T} \\
& +A_{9} x_{\mathrm{B}}^{0} \ln T
\end{aligned}
$$

in which $A_{1}$ to $A_{9}$ are the model parameters calculated by a least-squares analysis. ${ }^{1}$ The obtained overall MPD value for three investigated binary solvent mixtures was 4.2 .

The aim of this communication is to point out an alternative modification of the Jouyban-Acree model for representing the solubility of solutes in binary solvent mixtures at various temperatures and discuss its main advantages over the modifications made by Zhou et al. ${ }^{1}$

The van't Hoff equation is applicable to the ideal solutions, and in case of real pharmaceutical solutions, it is possible to use eq 4 when nonlinear van't Hoff plot is obtained. ${ }^{4}$ The basic Jouyban-Acree model has been employed in a number of recent reports by replacing the solubility of the solute in monosolvents, that is, $\ln \left(x_{\mathrm{A}}\right)_{\mathrm{B}, T}$ and $\ln \left(x_{\mathrm{A}}\right)_{\mathrm{C}, T}$, with the corresponding values from the van't Hoff equation and produced reasonably accurate results. ${ }^{5-7}$ In these works, we

Received: December 18, 2011

Accepted: February 27, 2012

Published: March 7, 2012 
Table 1. Model Constants of Equation 8 and the Mean Percentage Deviations (MPDs) of the Models

\begin{tabular}{|c|c|c|c|c|c|c|c|c|c|}
\hline cosolvent & $\alpha_{1}$ & $\alpha_{2}$ & $\alpha_{3}$ & $\alpha_{4}$ & $J_{0}$ & $J_{1}$ & $J_{2}$ & eq 8 & eq $6^{a}$ \\
\hline methanol & 1.624 & -2735.326 & 1.278 & -2680.714 & 165.814 & 138.636 & -239.647 & $5.0( \pm 2.9)$ & $4.9( \pm 2.9)$ \\
\hline ethanol & 2.281 & -2931.048 & 3.694 & -3781.579 & 118.947 & 367.199 & 17.676 & $5.4( \pm 4.4)$ & $5.2( \pm 4.3)$ \\
\hline glycol & 1.000 & -2526.984 & 3.162 & -2791.887 & 292.879 & -262.833 & $\begin{array}{l}222.971 \\
\text { overall }\end{array}$ & $\begin{array}{l}3.2( \pm 2.2) \\
4.5\end{array}$ & $\begin{array}{l}2.6( \pm 2.0) \\
4.2\end{array}$ \\
\hline
\end{tabular}

${ }^{a}$ Recalculated MPDs based on the reported data in the original reference. ${ }^{1}$

expressed the variation in $\ln \left(x_{\mathrm{A}}\right)_{\mathrm{B}, T}$ and $\ln \left(x_{\mathrm{A}}\right)_{\mathrm{C}, T}$ values in eq 2 as

$$
\begin{aligned}
\ln x_{\mathrm{A}, T}= & x_{\mathrm{B}}^{0}\left(\alpha_{1}+\frac{\alpha_{2}}{T}\right)+x_{\mathrm{C}}^{0}\left(\alpha_{3}+\frac{\alpha_{4}}{T}\right) \\
& +x_{\mathrm{B}}^{0} x_{\mathrm{C}}^{0} \sum_{i=0}^{n} \frac{J_{i}}{T}\left(x_{\mathrm{B}}^{0}-x_{\mathrm{C}}^{0}\right)^{i}
\end{aligned}
$$

or

$$
\begin{aligned}
\ln x_{\mathrm{A}, T}= & \alpha_{1} x_{\mathrm{B}}^{0}+\frac{\alpha_{2} x_{\mathrm{B}}^{0}}{T}+\alpha_{3} x_{\mathrm{C}}^{0}+\frac{\alpha_{4} x_{\mathrm{C}}^{0}}{T}+J_{0}\left(\frac{x_{\mathrm{B}}^{0} x_{\mathrm{C}}^{0}}{T}\right) \\
& +J_{1}\left(\frac{x_{\mathrm{B}}^{0} x_{\mathrm{C}}^{0}\left(x_{\mathrm{B}}^{0}-x_{\mathrm{C}}^{0}\right)}{T}\right) \\
& +J_{2}\left(\frac{x_{\mathrm{B}}^{0} x_{\mathrm{C}}^{0}\left(x_{\mathrm{B}}^{0}-x_{\mathrm{C}}^{0}\right)^{2}}{T}\right)
\end{aligned}
$$

Equation 8 was used to correlate the solubility of $(Z)-2-(2-$ aminothiazol-4-yl)-2-methoxyiminoacetic acid in three investigated solvent systems, and the model constants and the MPD values are listed in Table 1 . The overall MPDs of eqs 6 and 8 are 4.2 and 4.5, and relatively the same accuracies were obtained for correlated data using both models. It should be noted that eq 8 contains two fewer adjustable curve-fit coefficients and that some of the model constants of eq 6 possess a higher probability $(p>0.10)$, revealing that these constants are not statistically significant.

We also note that eq 8 can be trained using a minimum number of experimental data points and then be used to predict the solubility at other solvent compositions and temperatures of interest. To illustrate this application of the model, it has been trained using seven data points (two data points of solvent $B$ at the highest and lowest temperatures, the same data points for solvent $\mathrm{C}$, and three data points with different solvent compositions of the binary solvent), and then the remaining solubility data points were predicted using an interpolation technique. The obtained MPDs for aqueous mixtures of methanol, ethanol, and glycol were $10.6(N=73), 17.7$ (73), and $14.8(N=103)$, respectively, with the overall being 14.4. To compare similar data predicted by eqs 6 and 8 , both models were trained using 10 experimental data points (two data points of solvent $\mathrm{B}$ at the highest and lowest temperatures, the same data points for solvent $\mathrm{C}$, and six data points with different solvent compositions of the binary solvent), and the rest of data points were predicted using the trained models. The obtained MPDs for aqueous mixtures of methanol, ethanol, and glycol for eq 6 were $5.8(N=70), 5.5(70)$, and $5.5(N=100)$, respectively, with the overall 5.6. The corresponding values for eq 8 were $5.7(N=70), 5.6(70)$, and $5.7(N=100)$, respectively, with the overall 5.7 .
The main advantages that the Jouyban-Acree model has over the derived version for representing the solubility of solutes in binary solvent mixtures are: (1) a more accurate correlation of the solubility of drugs in binary solvents at various temperatures among similar algorithms employing equal number of curve-fitting parameters, (2) the prediction of the solubility using a minimum number of experimental data points with an acceptable prediction error, (3) theoretical justification of the model constants, ${ }^{8}$ (4) a uniform mathematical representation of solubility and other physicochemical properties, (5) the calculated equation coefficients for binary solvent mixtures which can be combined to estimate solute solubility in ternary and higher-order multicomponent systems, ${ }^{9}$ and (6) the availability of the globally trained versions of the model to predict the solubility of pharmaceuticals in mixed solvents at various temperatures employing the solubility data in monosolvents. ${ }^{10-12}$

Concerning these advantages, the results of testing the model on a large number of data sets examined, and the ease of the required calculations, it is recommended for use in the correlation and/or prediction of the solubility of pharmaceuticals in mixed solvents.

\section{AUTHOR INFORMATION}

\section{Corresponding Author}

*E-mail: ajouyban@hotmail.com.

\section{Notes}

The authors declare no competing financial interest.

\section{REFERENCES}

(1) Zhou, Z.; Qu, Y.; Wang, J.; Wang, S.; Liu, J.; Wu, M. Measurement and Correlation of Solubilities of (Z)-2-(2-Aminothiazol-4-yl)-2-methoxyiminoacetic Acid in Different Pure and Binary Mixtures of Water + (Ethanol, Methanol, or Glycol). J. Chem. Eng. Data 2011, 56, 1622-1628.

(2) Jouyban, A. Review of the Cosolvency Models for Predicting Solubility of Drugs in Water-Cosolvent Mixtures. J. Pharm. Pharm. Sci. 2008, 11, 32-58.

(3) Barzegar-Jalali, M.; Jouyban-Gharamaleki, A. A General Model from Theoretical Cosolvency Models. Int. J. Pharm. 1997, 152, 247250.

(4) Grant, D. J. W.; Mehdizadeh, M.; Chow, A. H. L.; Fairbrother, J. E. Non-Linear van't Hoff Solubility-Temperature Plots and Their Pharmaceutical Interpretation. Int. J. Pharm. 1984, 18, 25-38.

(5) Jouyban, A.; Shayanfar, A.; Acree, W. E. Jr. Solubility Prediction of Polycyclic Aromatic Hydrocarbons in Non-Aqueous Solvent Mixtures. Fluid Phase Equilib. 2010, 293, 47-58.

(6) Panahi-Azar, V.; Shayanfar, A.; Martinez, F.; Acree, W. E. Jr.; Jouyban, A. Thermodynamic Studies of Fluphenazine Decanoate Solubility in Propylene Glycol + Water Mixtures and Correlation with the Jouyban-Acree Model. Fluid Phase Equilib. 2011, 308, 72-77.

(7) Shayanfar, A.; Eghraray, S. H.; Sardari, F.; Acree, W. E. Jr.; Jouyban, A. Solubility of Anthracene and Phananthrene in Ethanol + 2,2,4-Trimethylpentane Mixtures at Different Temperatures. J. Chem. Eng. Data 2011, 56, 2290-2294. 
(8) Acree, W. E. Jr. Mathematical Representation of Thermodynamic Properties. Part II. Derivation of the Combined Nearly Ideal Binary Solvent (NIBS)/Redlich-Kister Mathematical Representation from a Two-Body and Three-Body Interactional Mixing Model. Thermochim. Acta 1992, 198, 71-79.

(9) Jouyban-Gharamaleki, A.; Clark, B. J.; Acree, W. E. Jr. Models to Predict Solubility in Ternary Solvents Based on Sub-Binary Experimental Data. Chem. Pharm. Bull. 2000, 48, 1866-1871.

(10) Jouyban, A.; Soltanpour, Sh.; Soltani, S.; Tamizi, E.; Fakhree, M. A. A.; Acree, W. E. Jr. Prediction of Drug Solubility in Mixed Solvents Using Computed Abraham Parameters. J. Mol. Liq. 2009, 146, 82-88. (11) Jouyban, A.; Shayanfar, A.; Panahi-Azar, V.; Soleymani, J.; Yousefi, B. H.; Acree, W. E. Jr.; York, P. Solubility Prediction of Drugs in Mixed Solvents Using Partial Solubility Parameters. J. Pharm. Sci. 2011, 100, 4368-4382.

(12) Abraham, M. H.; Acree, W. E. Jr. Partition Coefficients and Solubilities of Compounds in the Water-Ethanol Solvent System. J. Solution Chem. 2011, 40, 1279-1290. 